\title{
Unwaged Posts in UK Universities: Controversies and Campaigns
}

\author{
Kirsten Forkert* and Ana Lopes** \\ *Birmingham City University, Birmingham, UK, kirsten.forkert@bcu.ac.uk; **University of \\ the West of England, Bristol, UK, Ana2.Lopes@uwe.ac.uk
}

\begin{abstract}
This article examines unwaged posts at UK universities, using recent examples of advertised job posts. While unpaid work is common in the UK higher education system, unwaged posts are not. The posts under scrutiny in this article differ from traditional honorary titles as they target early career academics, who are unlikely to have a paid position elsewhere, rather than established scholars. The article contextualizes the appearance of these posts in a climate of increasing marketization of higher education, entrenching managerialism in higher education institutions, and the casualization of academic work. We also discuss resistance to the posts, arguing that the controversy surrounding unpaid internships in the creative industries created a receptive environment for resisting unwaged posts in academia. We analyze the campaigns that were fought against the advertisement of the posts, mostly through social media and the University and College Union. We explore the tactics used and discuss the advantages and limitations of the use of social media, as well as the role of trade unions in the campaigns against these posts, and we reflect on what future campaigns can learn from these experiences.
\end{abstract}

Keywords: universities, internships, academic labour, academia, precarity, unwaged work, social media, unions, casualization, activism, inequality

Acknowledgement: We wish to thank Vicky Blake for contributing to this article and other activists who shared their experiences with us.

\section{Introduction}

This article examines the phenomenon of unwaged posts in UK universities. It uses the examples of unwaged posts recently advertised at four higher education institutions as cases: unpaid research assistants at the University of Birmingham (UoB) and University College London (UCL) advertised in 2012; an "honorary junior research fellowship" at the University of Essex (UoE) advertised in 2013; and an unwaged "extracurricular" teaching post at Durham University, also advertised in 2013 (see the appendices for the adverts). The advertising of these posts provoked resistance on a national scale through public pressure, naming and shaming on social media, and campaigning by the University and College Union (UCU), causing the posts to be withdrawn (except for the post at Durham University). Subsequently, the universities issued defensive statements framing the unwaged posts as philanthropic goodwill, arguing they were "helping" postgraduates and recent postdoctoral researchers get teaching or research experience in a difficult job climate (Anna Freud Centre 2012; Birmingham Post 2012; University of Essex 2014).

In this article, we reflect on the extent to which these posts represent the exploitation of a worsening situation of labour precarity in the academic sector. We discuss these cases in the context of a hyper-competitive job market, which not only intensifies publishing demands on permanent staff, creating pressures to outsource routine teaching and research tasks to casualized workers, but also exacerbates desperation for postgraduates and early career academics for teaching and/or research experience. We reflect on a worrying normalization of the idea that academic work, particularly at the lower end of the professional hierarchy, does not have to pay a living wage, and that nobody's job is really secure. We also discuss the 
similarities between academic labour in the neoliberal university and cultural labour under precarious conditions.

It is in response to these deteriorating, generalizing conditions that the campaigns against the unwaged posts developed. We focus on these campaigns through an examination and thematic analysis of the expressions of public outrage and issues raised via union campaigns and social media. Finally, we will discuss how these campaigns led most of the universities involved, with the exception of Durham University, to withdraw the advertisements in question. We reflect on the potential of social media to capitalize on public outrage and enable a swift response, and we consider the limitations of relying on social media in such campaigns when the goal is to achieve permanent change.

\section{Context: Casualization and Precarity in UK Higher Education}

The cases explored in this article need to be understood in the context of debates surrounding precarity, that is, a broad state of existential, financial, and social insecurity that is underpinned by the flexibilization and casualization of labour markets (de Peuter 2011). Shortterm, insecure, and low-wage jobs are becoming the norm in sectors we used to see as secure. Isabell Lorey (2015) has recently argued that far from being an episodic condition, precarity is now normalized, while the welfare state is the exception. According to Lorey, the normalization of precarity has become an instrument of governance: it enables governing through insecurity. Through insecurity and fear, precarization embraces the whole of people's existence.

Internships are common in what are seen to be glamorous fields, such as politics, media, and the cultural industries (Curiale 2010; Perlin 2012; Intern Aware 2014; National Union of Journalists 2012; Carrotworkers' Collective 2012). Unwaged internships have been problematized for benefitting exploitative employers and those who can afford to work for free and thus restricting access to certain professions to those from privileged backgrounds. Internships started to become both common (Gregory 1998) and controversial in the 1990s, when 52 former interns of a U.S. public relations firm sued their employer for back wages (Perlin 2012,68 ) and "The Intern Trap," an article exposing the exploitation of unpaid interns in architecture, was published (Fisher 1994). However, the issue has gained special prominence since the Great Recession in 2008, which has had a significant impact on youth unemployment. In the academic sector, researchers expect internships will become even more common in the near future (Curiale 2010). Although unpaid internships are technically illegal in the UK, with the exception of specific circumstances such as student placements and work shadowing (United Kingdom Government 2014), monitoring and enforcement remain problematic.

Controversies surrounding unpaid internships in general are tied to their pedagogical, legal, and ethical implications (Burke and Carton 2013) and questions are raised concerning inequality, particularly with respect to the exclusion of those who cannot afford to work for free (or, in the UK, live in expensive cities such as London, where many of these opportunities are located) and the consequences of this for different fields and society as a whole. Commentators point to the "stark class divide between entry-level job seekers who can afford the luxury of unpaid experience and those who cannot" (Curiale 2010, 1534). Furthermore, the more prevalent unpaid internships become, the less incentive employers have to pay interns. Internships may also indirectly contribute to unemployment, as organizations realize that work can be done for free by unpaid interns (ibid., 1537). Sabina Siebert and Fiona Wilson (2013) analyze the consequences of unpaid internships for those who already work in the creative industries sector, highlighting the perspective of those who may be or are displaced by unpaid internships, as well as those who are excluded from taking part in unpaid internships.

Most literature on internships appears in the context of sectors such as politics, media, and cultural industries. In this article, however, we focus on a somewhat less glamorous sector, higher education, where unwaged positions are becoming more common. As with unpaid internships in other sectors, unwaged positions in higher education have the potential to ex- 
clude certain people from academic careers and contribute to the casualization of academic work. The framing of graduate teaching assistant work as "training" rather than work has been explored (see Krause et al. 2008, 5; Perlin 2012); however, the role of unwaged posts in the higher education sector, a similar and related issue, remains largely un-researched.

Part of the context of unwaged posts is the casualization or proletarianization of academic labour that has been underway for decades (see Wilson 1991; Guillory 1994; Aronowitz 2001). However, the phenomenon of unwaged academic posts has gained particular prominence since 1998, as the years that followed saw unprecedented changes impacting the higher education sector in the UK, which created an uncertain funding climate. Prior to 1998, students in the UK received grants to attend university and did not pay tuition fees. Fees were introduced in England in 1998 at $£ 1,000$ and grants were replaced with incomecontingent loans; different situations existed in Scotland, Northern Ireland, and Wales (UK House of Commons and Browne 2013). The passing of the 2004 Higher Education Act under the Labour government of Tony Blair allowed universities to charge up to $£ 3,000$ ( $£ 3,225$ after 2007) (ibid.). The Browne report, Securing a Sustainable Future for Higher Education: An Independent Review of Higher Education Funding and Student Finance (U. K. Government 2010), recommended the lifting of the fees cap and the removal of government funding for all courses, except "priority" courses, i.e., medical and some scientific courses, based on the principle of market liberalism (Couldry 2011). Despite widespread student protests (see Kumar 2011 for a discussion of the limitations of this movement), the cap to fees remained but was raised to $£ 9,000$. This was accompanied by cuts in direct university funding for subjects outside of science, technology, engineering, and medicine. The 2011 Higher Education White Paper also enabled a greater role for private colleges through easier criteria for institutions to call themselves "universities" and therefore access the student loan system (UK Department for Business, Innovation and Skills 2011; for analysis see McGettigan 2013).

What these reforms amounted to then was a re-classification of what a university should be: a move away from a view of a university education as a public good toward education as a commodity in a market that is only lightly regulated (Fenton 2011). Beyond these reforms, the sector has also been impacted by external factors, such as rising unemployment and pressures on household finances caused by the post-2008 economic recession. The combination of these changes has had significant impact on the academic workforce, which has been increasingly casualized and rendered precarious.

The casualization of the academic workforce is symptomatic of the neoliberalization of academia, and should be considered in relation to the changes discussed above. Employers have framed the use of casualized contracts in terms of "flexibility" and claim that only a small minority of staff are employed on such contracts, but figures recently obtained by the UCU through Freedom of Information requests suggest otherwise. According to these statistics, more than 40 percent of teaching-only staff in UK universities work on zero-hours contracts, ${ }^{1}$ while many more work under other forms of contractual casualization, such as hourly paid teaching (where employees are paid by the hour rather than an annual salary) and other temporary contracts (UCU 2013a). In fact, researchers claim that the number of lecturers and researchers in temporary, hourly paid, or zero-hour contracts has grown exponentially in recent years (Bauder 2006; Herbert, Hannam, and Chalmers 2002; Smith and Coombe 2006). In both the Australian (Coombe and Clancy 2002; Kimber 2003) and American (Bauder 2006) higher education sectors, nearly half of all teaching-related duties are undertaken by sessional staff (Halcomb et al., 2009, 528). In the UK, the number of temporary staff on teaching-only contracts increased by a third between 2009-2010 and 2011-2012 (Fazackerly 2013).

Moreover, the unwaged posts discussed in this article emerged within the context of the increasing use of graduate teaching assistants and graduate research assistants by UK universities. Such positions were not common a few decades ago, and can be seen as symptomatic of casualization and intensifying managerialism (Amaral, Meek, and Ingvild 2003;

\footnotetext{
${ }^{1}$ Zero-hours contract are a type of contract where "the employer is not obliged to provide the worker with any minimum working hours, and the worker is not obliged to accept any of the hours" (ACAS n.d.).
} 
Chandler, Barry, and Clark 2002). The effects of the expansion of the use of graduate teaching assistants on postgraduate researchers are pernicious. Instead of receiving a grant or scholarship to conduct doctoral research, increasing numbers of PhD students are now expected to pay tuition fees and teach or conduct "grunt" research work for low wages under such titles.

These conditions have also produced a situation where very few permanent entry-level posts exist compared to the numbers of applicants. In 2010 only 19 per cent of PhD graduates in the UK held permanent academic jobs three and a half years after completion (Else 2014). Within this hyper-competitive job market, a PhD qualification on its own is not enough, and both publications (particularly those which can boost a department's research culture) and substantial teaching experience have become standard expectations for hiring to a permanent post, allowing universities to justify unpaid posts of the kind investigated in this article as providing valuable teaching experience. Another aspect of this situation is the mounting publishing pressure for full-time academics. In order to satisfy the pressure to publish, academics are increasingly incentivized to outsource project fieldwork and or/lab research to (frequently low-paid) research assistants and routine teaching work to graduate teaching assistants. The latter are increasingly desperate to take on this sort of work for financial reasons (due to under-funding) and, faced with an extremely competitive job search, to gain and be able to demonstrate both teaching and research experience.

It is in this context of growing workforce casualization and marketization of post-secondary education in the UK that the cases explored in this article arise. Before we examine the specific cases however, we consider the emerging attitudes around unpaid work, which contribute to its justification as a necessary sacrifice for a rewarding and personally meaningful career. According to Andrew Ross, academic work shares characteristics with cultural work in that:

artistic and academic traditions extol sacrificial concepts of mental or cultural labour that are increasingly vital to newly important sectors of the knowledge industries. No longer on the margins of society, in Bohemia or the Ivory Tower, they are providing a rationale for the latest model of labour exploitation in core sectors of the new industrial order, and pioneering the workplace of tomorrow. (Ross 2000, 2)

Furthermore, Ross points out that unwaged work in the cultural industries (and increasingly in academia) is subsidized by workers themselves:

[...] the largest subsidy to the arts has always come from workers themselves. To this day, all such workers, even those employed on market-driven contracts, tend to earn compensation well below that commensurate with their skills and levels of educational attainment. The cruel indifference of the marketplace does not seem to deter the chronically discounted. Indeed, and largely because of artists' traditions of sacrifice, it often appears to spur them on in ways that would be regarded as self-destructive in any other economic sector. (ibid., 6)

Rosalind Gill also highlights the parallels between academics in the neoliberal university and cultural workers in precarious employment: "for example, DIY biographies, that is, the strong sense of needing to be adaptable and ready to try anything in one's working life, opportunities based significantly on reputation, and the prevalence of network sociality" $(2014,13)$. Given these parallels, in this article we borrow Ross's (2000) concept of self-subsidy to help us understand ongoing transformations in academia, where qualified and experienced tutors and lecturers perform a significant amount of labour that is unpaid. This concept of selfsubsidy is close to Angela McRobbie's (2010) analysis of "self-exploitation" on the basis of a passion for one's work, or what she calls the "pleasure in work" factor (McRobbie, 2015. However, Gill $(2014,25)$ argues that when it comes to academic work, "self-exploitation" may not be an accurate concept and instead urges researchers to develop a politicized vocabulary that will enable us to think about exploitation and privilege together in analyses of academic and cultural work. The normalization of a culture of overwork and subsidizing universi- 
ties by providing work that is not paid for helps explain, at least in part, the appearance of advertised unwaged positions.

As elsewhere, in higher education precarity is not only limited to those on temporary contracts. Gill (2014), for example, maintains that in the context of UK universities there is a sense that, to some extent, everyone feels their job to be insecure. The Research Excellence Framework (REF), an evaluation process for the allocation of research funding, has exacerbated these conditions. Like its predecessor, the Research Assessment Exercise, the REF requires academics whose contracts include research to have a selection of their publications evaluated and ranked according to a set of criteria, from 1 ("nationally recognized") to 4 ("world leading"), with only research outputs attaining 3 and 4 being funded. University departments and institutions compete against each other for the top scores, which then factor into league tables and other ranking systems. This procedure frames academics' publications as the "property" of individual departments and, for individual academics, functions as performance management. The consequence is that those academics who are not included in the REF are increasingly under threat of being demoted to teaching-only contracts. The REF has also had pernicious effects on hiring. The UCU's REFWatch blog has flagged "institutional gaming" in the hiring process, including the creation of "transfer markets" of research superstars (UCU 2013b) and also increasing pressures for early career academics to produce REF-ready outputs whilst employed "on a variety of precarious contracts, including hourly paid teaching (sometimes on zero hours contracts) and fixed-term contracts for short term research projects, making the production of the necessary outputs rather difficult to achieve" (UCU 2013c).

These circumstances require many academics, both on temporary and permanent contracts, to engage in a dual process of what Ursula Huws (2006) terms "begging and bragging." Huws contends that the academic labour process is permeated by continual rituals of supplication and boasting, for example, in the process of applying for jobs, funding, and research time. There is also a prevalence of working for free across all levels of the academic workforce, ranging from working beyond the hours of one's contract just to stay employable to performing tasks without pay such as peer reviewing academic articles.

Such conditions underpinning the academic labour process make it very difficult to develop solidarity among the workforce. Instead, there is an increasing sense that academics, regardless of their contractual situation, are constantly in competition against each other. As a result, many precarious academics feel they have no choice but to accept unwaged work as it becomes normalized and institutionalized.

\section{Unwaged Positions in UK Universities}

In this section we discuss four cases of unwaged work advertised in UK universities: unwaged research assistants at the UoB and UCL, an "honorary junior research fellowship" at the UoE, and "extra-curricular teaching opportunities" at Durham University (See Appendices: Adverts). Despite the above-discussed pressures to perform unpaid work and work more than what is technically required by one's contract, unwaged positions are not common in UK universities. However, and in contrast to other countries, there exists in many UK universities the possibility of appointing scholars to honorary titles such as research fellow, reader, or professor. Such titles confer an academic, typically employed by another university (often in a different country), access to the university facilities, and associate their name (often bearing prestige) to the institution to the latter's advantage. This would, in principle, be a mutually advantageous relationship. What is different about the posts under discussion in this article is that they target early career academics who are unlikely to hold a paid position elsewhere.

The first post that provoked a critical response was an "honorary research assistant" post at UoB, advertised on Jobs.ac.uk, an academic job search website, in June 2012. The job, connected to a research project on mental illness in children and adolescents, required "conducting clinical assessments of adolescents and young adults seeking help for mental health issues," as well as "ongoing assessment of participants and some data entry and manage- 
ment." The holder of the post was required to submit "a recent enhanced Criminal Records Bureau clearance," and to have access to his/her own vehicle to drive to work, although petrol costs were apparently to be covered (UCU 2012).

Shortly after the UoB position was posted, the Anna Freud Centre at UCL advertised for an unwaged research assistant for a project on health risks associated with depression. The post involved contacting and explaining the research project to participants, completing forms and filling out questionnaires, and entering data (Anna Freud Centre 2012). In June 2013, an "honorary junior research fellowship" was advertised at UoE. The advert stated that "whilst there is no salary attached to these fellowships the Fellows appointed will be entitled to shared office and study space equipped with computing facilities, and the use of all library and school services. Whilst there is no attendance requirement Fellows are expected to take part in school activities" (UoE 2013). The final case, "extra-curricular teaching" at Durham University, is the only post that was not withdrawn. In October 2013, Durham University advertised "extra-curricular teaching opportunities," explicitly framing them as "teaching experience" and a "voluntary development opportunity." The advert read:

The Department is offering a voluntary development opportunity for PhD students to apply to design and offer a short course of Extracurricular Seminars for undergraduate students. The scheme allows postgraduates to acquire valuable experience of designing and delivering an entire short taught course. If your application is successful, you will design and run an extra-curricular course comprising one contact hour per week for four weeks, primarily but not exclusively geared toward Level 1 undergraduates. [...] Your seminars will appear on your departmental training transcript. (Durham University 2013)

Both the casualization of academic work discussed earlier and the increasingly politicized nature of internships in the cultural industries (discussed elsewhere in this journal issue) made these unwaged posts controversial, provoking outrage and accusations of cynical exploitation.

The four unwaged posts provoked resistance for different reasons. The first two, at UoB and UCL, were research assistant posts, which involved carrying out assigned tasks on projects led by other academics. These positions were similar to unwaged internships elsewhere in that they involved performing routine tasks without payment. The UoB post also involved health and safety risks and additional costs. The third post was an "honorary stipendiary research fellowship," that is, in essence, an institutional affiliation, providing library and IT access, at UoE. This post was different in that unlike the research assistant posts it had previously been advertised for five years without concern. There is also a tradition at Oxford and Cambridge of offering honorary fellowships to staff with permanent academic positions at other universities (meaning that they are quite different from an internship in a conventional sense). However, the growing politicization of internships, combined with the ambiguous wording of the job advert (which included language framing it as a job), and its timing towards the end of the REF cycle (in relation to the institutional game-playing and intellectual property issues discussed earlier in this paper), contributed to the outrage provoked by the post. The final post discussed here, promising "extra-curricular teaching" at Durham University, was different from the other three in that it neither involved carrying out assigned tasks nor an institutional affiliation advertised competitively (with expectations attached). Rather, the position consisted of teaching undergraduate students unpaid as part of regularly timetabled sessions, and was framed as teaching experience-and can thus be understood in terms of the pressures to demonstrate this experience within the job market.

\section{Campaign Tactics and the Role of Unions}

In an atomized and hyper-competitive environment, academics regularly engage in individualized acts of resistance (Harvie 2006). In this section, however, we explore collective resistance and the role of unions in the response to these posts. Unions have been criticized for failing to recruit casualized employees, who have been traditionally seen as difficult to organize (Gallagher and Sverke 2005). However, unions can play a role in encouraging and 
creating solidarity among casualized workers. The University and College Union (UCU) is the main union in higher, further, and adult education in the UK, representing more than 116,000 staff at 715 workplaces (UCU South West, e-mail correspondence, December 17, 2014). UCU's structure includes a number of equality standing committees and special employment interest groups, one of which is the Anti-Casualisation Committee (ACC), which campaigns on behalf of fixed-term and hourly paid staff. The ACC produces specialist campaign materials and career advice materials tailored to the needs of casualized staff. It organizes regular training on anti-casualization campaigns and an annual day of action. By doing so it provides casualized staff with networking opportunities, something that the very nature of their contracts tends to render difficult. The ACC also produces a newsletter, hosts an e-mail discussion list, and maintains a visible presence on social media. Along with local UCU branches, informal networks, and individual campaigners, the ACC played a key role in the four cases discussed in this article.

Following the appearance of the adverts, social media-and particularly Twitter-were frequently used by academics and activists to raise awareness and to alert journalists to the unpaid posts, the adverts, and the issues surrounding them. The use of social media in such protests and campaigning is worthy of mention. Given the role the union played in the campaigns we discuss in this article, we are interested in how trade unions such as the UCU use social media. This topic has been investigated in previous literature, although this literature has suggested that unions are more commonly characterized as a residual form of activism, unlike the more spontaneous, populist forms of activism associated with the network society and social media (see, for example, Gerbaudo 2014, Castells 2007). Natalie Fenton and Veronica Barassi (2011) examine how trade unions in the UK use social media. They critique the assumption, particularly within the work of Bernard Stiegler $(2008,2009)$ and Manuel Castells (2009), that social movements can arise from "a realization of the politics of the self," arguing that such assumptions risk ignoring or marginalizing collective uses of social media $(2011,181)$. Based on a study of the Cuba Solidarity Campaign (CSC), which is a UK-based campaign to end the U.S. blockade of Cuba, Fenton and Barassi examine how social media can both present possibilities and challenges for union campaigns, enabling political participation in some cases, but undermining the specifically collective nature of campaigns (exacerbated by popular discourses about enabling individual creative autonomy but not solidarity) or degenerating into lazy "clicktivism" in others. As one of their respondents mentions: "members start to think that merely joining a Facebook group shows that you are committed. But actually it doesn't mean anything... it doesn't change things. There is too much information around, to be 'effective'" (Fenton and Barassi 2011,186). Unlike the example of the CSC examined by Fenton and Barassi, activists in the cases we describe were responding to particular situations (the advertising of the unwaged posts). Social media enabled rapid responses and generated media interest, but also presented certain limitations in the building of sustained campaigns.

The cases highlight how both the campaign responses and the statements issued by the universities present the posts as a response to a highly competitive job climate, in which early career academics are desperate to gain experience. The campaign responses highlight the discriminatory nature of the unwaged posts, as well as the damage that they could cause to higher education by restricting these opportunities to those who can afford to work for free. However, the public statements issued by universities present the posts as a form of training, support, and a philanthropic gesture of goodwill to desperate early career academics in need of "experience" (Anna Freud Centre 2012; Birmingham Post 2012; UoE 2014). The universities also claim they are democratizing the hiring process. These statements reveal deeper fault-lines around elitism in higher education, reflected in an implied normalization of unwaged posts and informal hiring. By framing the posts specifically as "training," rather than "work," they also infantilize early career academics as needing "help" in the form of unwaged opportunities.

In the next section, we turn to a discussion of the resistance against each of these unwaged posts through an analysis of social media interactions, blog entries, and online cam- 
paign communications and statements. In the process, we highlight the main themes that emerge from such communications.

\section{1. "Honorary Research Assistant," University of Birmingham}

The advertising of the honorary research assistant post at the University of Birmingham provoked outrage for UCU's ACC, particularly in light of the issues around casualization and inequality discussed earlier. Vicky Blake, ACC chair, flagged these issues in an e-mail to other committee members:

As a research assistant employed on a fixed term 0.3 FTE basis, I cannot adequately describe how angry this makes me. I rely on my (small) income to survive. To recruit candidates for 2 days a week in return for petrol money is disgusting, exploitative and will also mean that only someone with another income (or perhaps lottery winnings/trust fund?!) will be able to get the experience it offers. But with more "jobs" like this being advertised, will there even be any opportunities at the other end of something like this? (July 2, 2012)

Blake's e-mail expressed the frustration that these sorts of posts not only would be limited to those with access to private means, but also that there was no guarantee that they would lead to paid employment. A decision was made to react quickly, using both the ACC Twitter account and the personal Twitter accounts of several ACC members. This use of social media is significantly different from that described by Fenton and Barassi (2011) in the case of the Cuba Solidarity Campaign, as in this case the individual and collective uses of Twitter were seen to complement each other. Parody was also used as a strategy to raise issues about the unfairness of the post, as Blake described:

We developed a campaign around making mock applications to the listed e-mail address, for example offering to cycle the entire way from my home (many miles) to make it affordable, if only they would allow me to sleep under the desk to save energy in the week. This caught on with a number of people doing similar (or writing in as if they were totally privileged making the other side of the case). (e-mail correspondence, April 27, 2014)

There were also attempts to raise the issue within the context of open chats in the Guardian Higher Education Networks (the Higher Education section of the Guardian newspaper), such as the discussion provoked by the article "Freelance, Fixed-term or Part-time: Is this the Future of Academic Careers?" (Anyangwe 2012). The issue of unwaged positions was also debated on \#phdchat and \#ecrchat Twitter discussions, forums normally dedicated to career advice. Attempts were made to involve journalists in the discussion, as in a debate using \#phdchat which highlighted the difficulties of turning down unwaged work within the context of informal hiring practices in academia.

These debates drew out some of the ambivalence around the issue, including the perception that opportunities within academia frequently develop out of informal relationships, and the advertising of such posts simply formalizes them. This shows that while these posts did provoke outrage, responses are not unanimous in such cases, as some might feel they have no choice but to apply for these kinds of posts given the difficult conditions faced by precariously employed scholars.

The online discussions were followed by official communications. The UCU branch at UoB had been made aware of the post, particularly through postgraduate students "via less formal activist networks/channels" such as the now-defunct Postgraduate Workers' Association (Vicky Blake, email correspondence, April 27, 2014). The UCU's headquarters then put out a press release condemning the post, stating that "not paying researchers undermines the principles of equal pay and is discriminatory" and also making the point that "clearly not everyone can afford to work for nothing" (UCU 2012).

The post was withdrawn in early July of 2012, and the UoB released a statement framing the post as training and support. The response also claimed the university was merely formalizing what would normally have been an informal process: "rather than responding to 
individual enquiries, which is common practice, the university wanted to make this opportunity available to all and not just favour those with existing networks and contacts" (Jump 2012). The University's spokesperson also told the Birmingham Post that, "The University is strongly committed to providing appropriate training and support to students and graduates" (Birmingham Post 2012).

The framing of these posts as "training and support" rather than "work" is significant in absolving the University from its responsibility as an employer. It also represents an attempt to win public sympathy by explicitly referring to (or at least alluding to) the difficulty faced by many PhD candidates and early career academics by offering "experience" in an extremely competitive labour market, and depicts institutions as providing support and training opportunities in the form of unwaged posts. This is consistent with a wider tendency to frame unwaged internships in a range of sectors in terms of their specific benefit to the post-holder, rather than as an activity that would benefit both the intern and the employer. For example, in a semantic network analysis of paid and unwaged internship offer letters, Maynard (1997) found that words connoting benefit to the post-holder were used more frequently in offers of unwaged internship pitch letters than in offers of paid internships. The most commonly used "benefit" word used was "opportunity," often linked to the word "experience."

However, the dangers of the institutionalization of unwaged work were outlined in a collectively written letter to the Vice-Chancellor from the UoB UCU branch and others calling for all posts in the future to be properly remunerated:

If the UoB or others like it were to build unpaid positions into its structure in a serious way then a career within universities would become unaffordable to a vast swath of the population. This is yet another example where opportunities for young people are becoming far more based on ability to pay over the ability of the student themselves. (Craig 2012)

The letter established the connection between the unwaged posts and other ways in which young people are now living in an increasingly unequal society (exemplified by the increase of university tuition fees to $£ 9,000$, implied by the letter).

\subsection{Unwaged Research Assistant, Anna Freud Centre, University College London}

In the summer of 2012 the Anna Freud Centre at University College London (UCL) advertised an unwaged research assistant post. This provoked further concerns about the role of unpaid work in research projects, and more generally about the normalization and institutionalization of unwaged posts.

These concerns motivated postgraduate student and UCU activist Bill (pseudonym) to become involved in the campaign:

I got involved because I thought it was exploitative to extract unpaid labour from early career researchers by playing on desperation caused by the state of the academic career ladder and job market; because research institutions should be fighting their continued underfunding by government, not hiding, legitimising and potentially entrenching it by adapting and shifting to a reliance on unpaid work; and because the more that career progression depends on your capacity to spend extended periods working without income, the more exclusive academic careers will become. That not only locks people out and entrenches privilege, but also stands to damage the academy itself, by narrowing the perspectives and experiences of the community that produces research. (e-mail correspondence, May 19, 2014)

As with the UoB post, Twitter was used to name and shame:

I was then one of the people who started putting it out on Twitter-that's what really got it picked up, and pretty soon the story had created a minor storm, all over Twitter and with public commentators writing very critically, including high profile ones like [science commentator] Ben Goldacre. (ibid) 
An open letter was also posted to the Postgraduate Workers Association blog, highlighting how such posts exploit the desperation of postgraduates and early career researchers, legitimate the underfunding of research, and threaten to restrict careers in academia to the privileged (2012). Bill also felt one of the successes of the campaign was to capitalize "on a general level of semi-latent concern that was already out there about unpaid internships" (Bill's e-mail correspondence 19 May 2014)—notably making the connections between unwaged posts in academia and internships in other fields. The key issues raised by the campaign reflected concerns around internships in general, including the inaccessibility of desirable professions (in this case academia), the damaging belief that personally meaningful work does not have to be paid a living wage, the exploitation by employers of a highly competitive job climate, and the dangers of using unwaged internships to replace paid jobs. The familiarity of these concerns highlights similarities in the labour politics characterizing academia and fields such as the cultural industries in which unpaid internships became controversial.

On August 8, 2012, the UCU branch at UCL also issued an open letter to the Pro Vice Chancellor and the head of the Psychoanalysis Unit, arguing that unwaged posts harm research and calling for the University's senior management to "endorse and join those protests [about the underfunding of Higher Education] as a more just and appropriate response to the underfunding crisis than asking early career researchers, who are not responsible for it, to shoulder the burden" (University College London UCU 2012).

In "Another Unpaid Researcher Post, This Time at UCL. Shameful," Goldacre made many similar arguments: that such posts damage academia, as they already have media and politics, where

it is now recognized that unpaid internships are harmful to the culture of these professions: unpaid entry posts mean that the children of wealthy parents get in, get ahead, and do better, because their families can afford to give them money to pay rent and live in London while they earn no salary. (Goldacre 2012)

Others, such as blogger Martin Eve, also framed these posts as exploitative of younger generations: "Yet again a certain group of people are being screwed over [...] guess who? That's right! The people who paid tuition fees to go to university and are now trying to get their first academic post" (2012a).

Writing in the Guardian's Higher Education Network, Eve also argued that these posts create a race to the bottom in wages, pointing out the contradictions between the exclusivity of unwaged posts and imperatives to expand university education to a wider section of the population:

This setup, which confuses privilege with perseverance, creates several additional problems for academia. At a time when we are trying to ensure the continued diversity of our student body, we are restricting to a specific socio-economic class the pool from which applicants are drawn to sit on the other side of the desk. (Eve 2012b)

Moreover, Eve argued that unwaged posts give the impression that "the university is wellfunded" while in reality "quiet exploitation goes on undercover" (ibid.). That is, students may assume their lecturers are paid properly, and, if, for example, money is invested in buildings and facilities, that universities are in good financial health, without realizing that teaching or research are being performed unwaged.

In response to this public protest, UCL withdrew the post, issuing the following statement, which (similarly to the UoB statement) framed the post as training and "experience":

Their investment of time in learning these skills in methods of assessment, both physiological and psychological, would have served young people extremely well in terms of finding suitable paid employment on a wide range of research studies. (Anna Freud Centre 2012) 
The statement also pointed out that "none of the senior researchers involved will receive financial remuneration for the time they invest" (ibid.), ignoring the fact that the researchers involved presumably have permanent posts and research forms part of their workload (bearing in mind the issues discussed earlier).

Both the UoB and UCL posts were for research assistants, and thus involved working on others' projects (see Harvie 2000), and in many cases on the mundane but necessary tasks of research projects. The reactions caused by both posts could in part be attributed to contradictions between their status as "work" and their framing as "training" and "experience." However, the two cases we turn to now are less clear-cut.

\subsection{Honorary Junior Research Fellowship, University of Essex}

The advertisement of an "honorary junior research fellowship" at the University of Essex in June 2013 also provoked negative responses, such as this tweet, which, significantly, mentions UoE's official Twitter account:

Wow what an awesome opportunity! you have just finished your $\mathrm{PhD} \&$ now you may apply for an UNPAID job @Uni_of_Essex http://www.jobs.ac.uk/job/AGQ626/nonstipendiary-junior-research-fellowships/ ... (Schaefer 2013)

In an email to the national UCU activists' list, one of the authors of this article flagged the post:

It's essentially a research post with no salary attached. It also says "whilst there is no attendance requirement Fellows are expected to take part in school activities" - presumably unpaid. http://www.jobs.ac.uk/job/AGQ626/non-stipendiary-junior-research-fellowships/. I've spoken to a few other people and they've mentioned that other universities have advertised similar posts in the past. In the current climate, these sorts of posts could exploit desperate people, similar to unpaid internships. (June 2, 2013)

The UoE post could be interpreted as attempting to emulate the Oxford and Cambridge fellowship models, and, by implication, the prestige of these institutions. However, it presented what was in reality an institutional affiliation, desk space, and internet access as a "junior researcher post" and advertised it competitively. The requirement to participate in school activities (notably not defined in the advert) framed the post at least partly within the terms of employment (otherwise no such expectations would exist). It also means that the post-holder would play a role within the "REF environment" (the overall research culture), which accounts for 15 percent of REF funding (the post-holder would not be submitted as an individual researcher, but this was not made clear in the advert, although it was eventually clarified within the withdrawal statement).

The post was withdrawn after complaints from the UoE UCU branch. In response, the university issued this statement:

Our Junior Research Fellowship scheme was introduced five years ago and has been extremely successful in supporting post-doctoral students at the very beginning of their careers. However, in the current climate, where unpaid positions are proliferating, there is a danger that our intentions for the scheme are at risk of being misunderstood and misrepresented. (UoE 2013)

As mentioned, the post had been advertised for five years without controversy. However, increasing competition for jobs, casualization, and the intellectual property issues associated with the REF made it contentious, a fact acknowledged in the withdrawal statement. More generally, the broader controversy over internships had led to very similar questions being asked about academia that had been asked about internships in the cultural industries: If unwaged internships become a standard prerequisite for getting a job in academia, does this result in the exclusion of those from less privileged backgrounds from the field, and in what ways does this restrict the production of knowledge? Writing about unwaged internships in 
journalism in the United States, David Dennis Jr. argues that inequity of access results in those with first-hand experience of inner-city poverty, crime, and racism being shut out "from the national conversation" and thus not being able to "influence the direction of national discourse" (2013). Similar questions need to be asked about the implications of casualization and unwaged posts on teaching, research, and public debate.

Another similarity to the kinds of discourses and controversies characterizing unwaged internships was the framing of the post as training and support, and, more generally, an offer of "help" in a very difficult climate which would benefit the post-holder (similar to the internship offer letters in the Maynard study mentioned earlier). There was no discussion of how the University itself would benefit from the involvement of the research fellow in "school activities."

Following the withdrawal of the post, one of the authors of this article became part of an email exchange with the individual at UoE who had advertised the post. In that exchange, the author said:

I originally flagged up this post... because it was advertised as a competitive post, rather than simply offered as an affiliation [for PhD students without an academic post]; and that it sets a disturbing precedent in that, through being framed as a 'research fellowship', it is an appointment that could be listed on a CV that is limited to those who can afford to go without pay [...] Also-on a personal note-I am an early career researcher, having completed my PhD two years ago. I am now lucky to be employed full-time as a lecturer (after 8 job interviews and 2 temporary contracts) so I am well aware of the competitive nature of the job market at the moment, and many of my former classmates are struggling. (June $15,2013)$

Others in the email discussion pointed out that presenting access to a desk, computer, and online journals as a research post will make the post-holder look as though he/she has "research experience" and thus gain comparative advantage in the job search.

\subsection{Extra-curricular Teaching, Durham University}

Like the other unwaged posts, the "extra-curricular teaching" post advertised at Durham University provoked resistance and was debated in Palatinate, the University's student newspaper. A PhD student (who wished to remain anonymous) was quoted in the newspaper as saying, "I teach a few classes and it's incredibly useful for postgraduates to have the opportunity to do that, especially if you are not funded and need the extra money [...] I personally wouldn't volunteer to do any teaching for free" (cited in Bransgrove 2013). UCU Headquarters also sent out a press release stating that they had received a letter from the Director of Human Resources at the Durham University stating that "it is neither policy nor practice at Durham to recruit unpaid research staff" (UCU 2013d), pointing out the contradictions between the letter and the advertising of the posts.

However, in an article in the Independent, a mainstream daily newspaper, the University spokesperson claimed that the seminars had been set up in response to "demand from our postgraduate students, who wanted to broaden their teaching experience for their own professional development" (Mendelsohn 2013). This claim could be interpreted both as an attempt to disavow responsibility and as reflecting (and possibly exploiting) desperation for teaching experience and the resulting willingness (if the claim is true) to teach for free in order to gain this experience. Characterizing the post as an individual choice (as in desires to "broaden their teaching experience for their professional development") conceals how such "choice" might be underpinned by hierarchies of privilege within an extremely competitive environment; one where casualized staff, as well as many staff on permanent contracts, are frequently not paid for the full range of their duties. It is also worth reflecting on Gill's critique of "self-exploitation" as blaming individuals $(2014,25)$, and, in this way, ignoring the conditions and power structures that lead to apparently self-exploitative behaviour. It is possible that this rhetoric of choice (in addition to the lack of a visible campaign that marked the other cases) contributed to the post not being withdrawn. 


\title{
5. Conclusion
}

This article has explored the appearance of advertisements for unwaged posts at four UK universities. We have discussed this phenomenon in the context of precarity, casualization of work, and significant reforms to the UK higher education sector. Moreover, we have drawn connections between the controversy surrounding unpaid internships in the creative industries and academia by discussing aspects of the "mental labour problem" (Ross 2000) that characterize labour in both academia and the creative industries. The issues raised by campaigns against unpaid work in the cultural industries also provided a vocabulary for articulating the issues, particularly around how it would exclude those who could not work for free from desirable professions. We analyzed cases of resistance against the advertisement of unwaged posts in academia, cases which may signal a growing critique of the tendency to tolerate self-exploitation.

Despite the fact that the campaigns represented important successes in that they forced most of the posts to be withdrawn, there were limitations to the campaigns we analyzed. The starkest one may have been the fact that the campaigns and activists involved were not able to consolidate these quick successes into long-term change. Indeed, this was mentioned by Bill in reflecting on the limitations of the UCL campaign:

\begin{abstract}
We attempted to press for a revision of internal policies that would be a more permanent solution. However, that's where we fell down-we failed to follow through and effectively capitalise on the situation, and the issue kind of died away before we'd secured a more permanent change. Perhaps one factor here was our failure to turn the publicity campaign into an industrial one-we didn't get workers and students in the university organised into the kind of campaign on the ground that could have generated the necessary lasting pressure [...] (email correspondence, May 19, 2014)
\end{abstract}

A more permanent solution would involve, as Bill suggests, policy changes designed to prevent such posts from being advertised in the future. This would require pro-active involvement of casualized staff and early career academics in the union, as well as greater overall awareness of the conditions (e.g., scarcity in the job market, the neoliberalization of the university) contributing to such posts being advertised.

A possible reason for why more sustained gains were not achieved may lie in the strategies adopted, specifically the great reliance on social media to organize the campaigns. An important lesson deriving from the cases examined here is that the utilization of social media is useful for sparking interest and creating momentum. As Bill pointed out, the use of social media allowed the activists to capitalize on public outrage and respond swiftly. However, social media as a key campaign tool can be, in our view, of limited use in the long term. Bill alludes to this limitation in the following excerpt from an e-mail communication:

Regardless, I think that's probably an important general lesson-you can get quick wins from publicity-based efforts, that play on the PR effects of outrage in the media and social media, but that can't substitute for the slower work of building a lasting level of organisation among workers and in a student body, allowing them to exert real power in our education institutions. (Bill's email correspondence, 19 May 2014)

Another significant factor affecting the outcome of these cases is the relative lack of clout of the ACC within UCU, despite the important role it has played within these campaigns (although it has since become more prominent). This is partly explained by the fact that casualized academic staff are still largely under-represented within the union's membership and governance. In higher education, as in other sectors, casualized staff is less likely to be union members than permanent members of staff (Sverke et al. 2004).

Ultimately, the difficulties presented by the wider political and employment-relations climate should not be underestimated. The normalization of precarity and the neoliberalization of academia are significant barriers to solidarity and collective rejections of further exploitation. While, as we have shown, these processes do not make resistance impossible, they do 
present some very concrete challenges. The impulse to keep one's head down for fear of being branded a "troublemaker" can be very strong, and the continual condition of being in competition with one's peers can make collective action very difficult.

Nevertheless, important lessons can be learned from these campaigns. They are significant in terms of the rapid responses they triggered, as well as the multiple approaches taken (including blog posts, alerting journalists, social media) by commentators, campaigners, and the UCU. They represent important successes in terms of challenging the normalization and institutionalization of unwaged teaching and research, since the campaigns were successful in moving the universities to remove the advertisements and unwaged positions, with the exception of Durham. These campaigns are especially meaningful in that they also effectively capitalized on the mounting public outrage around unwaged internships in the cultural industries and politics. As such, they may constitute inspiration for activists elsewhere, as proof that unwaged work and precarity can be successfully challenged.

\section{References}

ACAS. n.d. Zero Hours Contracts. Accessed December 28, 2014. http://www.acas.org.uk/index.aspx?articleid=4468.

Amaral, Alberto, Vincent Meek and Larsen Ingvild. 2003. The Higher Education Managerial Revolution? Boston, M.A.: Kluwer Academic Publishers.

Anna Freud Centre. 2012. Statement Regarding the Recently Advertised ERIC-D Pilot Study Internships (02.08.2012). Accessed May 5, 2014. http://www.annafreud.org/jobs.php?id=350.

Anyangwe, Eliza. 2012. Freelance, Part-time or Fixed-term: Is this the Future of Academic Careers? The Guardian, July 11. Accessed April 15, 2014. http://www.theguardian.com/higher-educationnetwork/blog/2012/jul/11/careers-options-for-academics.

Aronowitz, Stanley. 2001. The Last Good Job in America. Lanham, M.D.: Rowman and Littlefield.

Bauder, Harald. 2006. Learning to Become a Geographer: Reproduction and Transformation in Academia. Antipode 38 (4): 671-679.

Birmingham Post. 2012. University of Birmingham Withdraws Unpaid Intern Advert After Protests. Birmingham Post, July 5. Accessed March 10, 2014. http://www.birminghampost.co.uk/news/localnews/university-birmingham-withdraws-unpaid-intern-3910956.

Bransgrove, Charlotte. 2013. Durham University Criticised for Offering Voluntary Unpaid Teaching Opportunities. Palatinate, October 24. Accessed May 1, 2014. http://www.palatinate.org.uk/?p=42093.

Burke, Debra and Robert Carton. 2013. The Pedagogical, Legal, and Ethical Implications of Unpaid Internships. Journal of Legal Studies Education 30 (1): 99-130.

Carrotworkers' Collective. 2012. Surviving Internships: A Counter Guide to Free Labour in the Arts. Accessed January 8, 2015. https://carrotworkers.files.wordpress.com/2009/03/cw web.pdf.

Castells, Manuel. 2007. Communication, Power and Counter-Power in the Network Society. International Journal of Communication 1: 238-266.

Castells, Manuel. 2009. Communication Power. Oxford: Oxford University Press.

Coombe, Kennece and Susan Clancy. 2002. Reconceptualizing the Teaching Team in Universities: Working with Sessional Staff. International Journal for Academic Development 7 (2):159-166.

Chandler, John, Jim Barry and Heather Clark. 2002. Stressing Academe: The Wear and Tear of the New Public Management. Human Relations 55 (9): 1051-69.

Couldry, Nick. 2011. Fighting for the University's Life. In The Assault on Universities: a Manifesto for Resistance, edited by Michael Bailey and Des Freedman, 37-46. London: Pluto.

Craig, Hattie. 2012. Letter to the University of Birmingham Vice-Chancellor. Facebook post. Accessed June 1, 2014. https://www.facebook.com/notes/hattie-craig/no-to-unpaidunwaged-work-an-openletter-to-the-vc/10151066897366894.

Curiale, Jessica L. 2010. America's New Glass Ceiling: Unpaid Internships, the Fair Labor Standards Act, and the Urgent Need for Change. Hastings Law Journal 61: 1531-1560.

de Peuter, Greig. 2011. Creative Economy and Labor Precarity: A Contested Convergence. Journal of Communication Inquiry 35 (4): 417-425.

Dennis, Jr., David. 2013. Unpaid Internships are Ruining Journalism. The Guardian, 28 May. Accessed January 5, 2015. http://theguardian.com/commentisfree/2013/may/28/unpaid-internshipsprivilege-ruin-journalism.

Durham University. 2013. Extracurricular Seminars. Accessed May 10, 2014. https://www.dur.ac.uk/theology.religion/postgrad/prof.dev/extracurricular.seminars/. 
Else, Holly. 2014. The PhD Experience: This Far and No Further. Times Higher Education, August 14. Accessed September 3, 2014. http://www.timeshighereducation.co.uk/features/the-phd-experiencethis-far-and-no-further/2015113.fullarticle.

Eve, Martin. 2012a. More Unpaid Academic Positions and Apparent "Culture of Entitlement." Accessed May 15, 2014. https://www.martineve.com/2012/08/02/more-unwaged-academic-positionsand-apparent-culture-of-entitlement.

Eve, Martin. 2012b. Unpaid Research Internships Reveal a Dangerous Hypocrisy in Academia. Guardian, August 2. Accessed May 15, 2014. http://www.theguardian.com/higher-educationnetwork/blog/2012/aug/02/unpaid-research-internships-academic-hypocrisy.

Fazackerly, Anna. 2013. Why are Many Academics on Short-Term Contracts for Years? The Guardian, February 4. Accessed January 5, 2015. http://www.theguardian.com/education/2013/feb/04/academic-casual-contracts-higher-education.

Fenton, Natalie. 2011. Impoverished Pedagogy, Privatised Practice. In The Assault on Universities: $A$ Manifesto for Resistance, edited by Michael Bailey and Des Freedman, 103-110. London: Pluto.

Fenton, Natalie and Veronica Barassi. 2011. Alternative Media and Social Networking Sites: The Politics of Individuation and Political Participation. The Communication Review 14: 179-196.

Fisher, Thomas. 1994. The Intern Trap: How the Profession Exploits its Young. Progressive Architecture 75 (7): 69-73.

Gallagher, Daniel G. and Magnus Sverke. 2005. Contingent Employment Contracts: Are Existing Theories Still Relevant? Economic and Industrial Democracy 26 (2): 181-203.

Gerbaudo, Paolo. 2014. Populism 2.0 Social Media Activist, the Generic Internet User, and Interactive Direct Democracy. In Social Media, Politics and the State: Protests, Revolutions, Riots and Policing in the Age of Facebook, Twitter and YouTube, edited by Daniel Trottier and Christian Fuchs, 6787. London: Routledge.

Gill, Rosalind. 2014. Academics, Cultural Workers and Critical Labour Studies. Journal of Cultural Economy 7 (1): 12-30.

Guillory, John. 1994. Literary Critics as Intellectuals: Class Analysis and the Crisis of the Humanities. In Rethinking class: Literary Studies and Social Formations, edited by Wai-Chi Dimock and Michael T. Gilmore, 107-149. New York: Columbia University Press.

Goldacre, Ben. 2012. Another Unpaid Researcher Post, This Time at UCL. Shameful. Accessed May 10, 2014. Post archived at http://web.archive.org/web/20120804184856/http://bengoldacre.posterous.com/another-unpaidresearcher-post-in-uk-academia.

Gregory, David. 1998. The Problematic Employment Dynamics of Student Internships. Notre Dame Journal of Law, Ethics and Public Policy 12: 227-64.

Halcomb, Elizabeth, Sharon Andrew, Kath Peters, Yenna Salamonson and Debra Jackson. 2009. Casualization of the Teaching Workforce: Implications for Nursing Education. Nurse Education Today 30 (6): 528-532.

Harvie, David. 2000. Alienation, Class and Enclosure in UK Universities. Capital \& Class 71 (Summer): 103-132.

Harvie, David. 2006. Value Production and Struggle in the Classroom. Capital \& Class 88 (Spring): 133.

Herbert, Debra, Rachel Hannam and Denise Chalmers. 2002. Enhancing the Training, Support and Management of Sessional Teaching Staff (HER02448). Accessed July 20, 2015 http://publications.aare.edu.au/02pap/her02448.htm.

Huws, Ursula. 2006. Begging and Bragging: the Self and the Commodification of Intellectual Activity. Inaugural Professorial Lecture, Working Lives Research Institute, London Metropolitan University, June 7. Accessed August 27, 2014. http://www.asah09.dsl.pipex.com/uhinaugural.pdf.

Intern Aware. 2014. About Us. Accessed July 20, 2015. http://www.internaware.org/about_us.

Jump, Paul. 2012. Advert for Unpaid Research Position Withdrawn. Times Higher Education, July 2. Accessed April 1, 2014. http://www.timeshighereducation.co.uk/420451.article.

Kimber, Megan. 2003. The Tenured "Core" and the Tenuous "Periphery": The Casualisation of Academic Work in Australian Universities. Journal of Higher Education Policy and Management 25 (1): 41-50.

Krause, Monika, Mary Nolan, Michael Palm and Andrew Ross. 2008. The University Against Itself: The NYU Strike and the Future of the Academic Workplace. Philadelphia: Temple University Press.

Kumar, Ashok. 2011. Achievements and Limitations of the UK Student Movement. In The Assault on Universities: A Manifesto for Resistance, edited by Michael Bailey and Des Freedman, 132-142. London: Pluto

Lorey, Isabell. 2015. State of Insecurity: Government of the Precarious. London: Verso. 
Maynard, Michael L. 1997. Opportunity in Paid vs. Unpaid Public Relations Internships: A Semantic Network Analysis. Public Relations Review 23 (4): 377-390.

McGettigan, Andrew. 2013. The Great University Gamble: Money, Markets and the Future of Higher Education. London: Pluto.

McRobbie, Angela. 2010. Re-thinking Creative Economy as Radical Social Enterprise. Sociology-ofCulture Blog. Accessed June 8, 2014. http://www.variant.org.uk/pdfs/issue41/amcrobbie41.pdf.

McRobbie, Angela. 2015. Is Passionate Work a Neoliberal Delusion? OpenDemocracy, April 22. Accessed July 20, 2015. https://www.opendemocracy.net/transformation/angela-mcrobbie/ispassionate-work-neoliberal-delusion.

Mendelsohn, Tom. 2013. Teaching is Not its Own Reward: Durham University in Unpaid Jobs Row. Independent, October 21. Accessed May 1, 2014. http://www.independent.co.uk/student/news/teaching-is-not-its-own-reward-durham-university-inunpaid-jobs-row-8894458.html.

National Union of Journalists. 2012. Submission to the Low Pay Commission on Internships. Accessed December 28, 2014. http://www.nuj.org.uk/documents/the-nujs-submission-to-the-low-paycommission-on-internships/.

Perlin, Ross. 2012. Intern Nation: How to Earn Nothing and Learn Little in the Brave New Economy. London: Verso.

Postgraduate Workers Association. 2012. Beating Unpaid Internships at UCL. Accessed May 28, 2014. http://postgraduateworker.wordpress.com/2012/08/14/beating-unpaid-internships-at-ucl/.

Ross, Andrew. 2000. The Mental Labor Problem. Social Text 18 (2): 1-31.

Schaefer, Mirko Tobias. 2013. Twitter post, June 5, 5:13 am. Accessed May 10, 2014. https://twitter.com/mirkoschaefer/status/342252743890706432.

Siebert, Sabina and Fiona Wilson. 2013. All Work and No Pay: Consequences of Unpaid Work in the Creative Industries. Work, Employment and Society 27 (4): 711-721.

Smith, Erica and Kennece Coombe. 2006. Quality and Qualms in the Marking of University Assignments by Sessional Staff: An Exploratory Study. Higher Education 51 (Spring): 45-69.

Stiegler, Bernard. 2008. "The Alternative of Metadata: Automated Voluntary

Servitude or Economy of Contribution." Lecture, Force of Metadata

Conference, Goldsmiths, London, UK, November 28.

Stiegler, Bernard. 2009. Teleologics of the Snail: The Errant Self Wired to a WiMax

Network. Theory, Culture and Society 26 (2-3): 33-45.

Sverke, Magnus, Johnny Hellgren, Katharina Näswall, Antonio Chirumbolo, Hans De Witte and Sjoerd Goslinga. 2004. Job Insecurity and Union Membership: European Unions in the Wake of Flexible Production. Brussels: P.I.E.-Peter Lang.

United Kingdom Department for Business, Innovation and Skills. 2011. Putting Students at the Heart of Higher Education. Accessed June 5, 2014. https://www.gov.uk/government/news/puttingstudents-at-the-heart-of-higher-education.

United Kingdom Government. 2010. Securing a Sustainable Future for Higher Education: An Independent Review of Higher Education Funding and Student Finance [Browne Report]. Accessed July 20, 2015.

https://www.gov.uk/government/uploads/system/uploads/attachment data/file/422565/bis-10-1208securing-sustainable-higher-education-browne-report.pdf.

United Kingdom Government. 2014. Employment Rights and Pay for Interns. Accessed June 72014. https://www.gov.uk/employment-rights-for-interns.

United Kingdom House of Commons and Michael Brown. 2013. Tuition Fee Statistics (Briefing Paper). Accessed June 5, 2014. http://www.parliament.uk/briefing-papers/SN00917.pdf.

University and College Union. 2012. Universities Should Pay Researchers. Accessed January 5, 2015. http://ucu.org.uk/index.cfm?articleid=6159.

University and College Union. 2013a. Over Half of Universities and Colleges use Zero-hour Contracts. Accessed January 5, 2015. http://www.ucu.org.uk/6749.

University and College Union. 2013b. Quality Thresholds and Institutional Gaming. REFWatch. Accessed August 30, 2014. http://ref.web.ucu.org.uk/2013/09/23/quality-thresholds-and-institutionalgaming/.

University and College Union. 2013c. Impact of the REF on Early Career Academics. REFWatch. Accessed August 30, 2014. http://ref.web.ucu.org.uk/2013/10/01/impact-of-the-ref-on-early-careeracademics/.

University and College Union. 2013d. Durham University in Unpaid Jobs Row. Accessed May 1, 2014. http://www.ucu.org.uk/index.cfm?articleid=6800. 
University College London University and College Union. 2012. Letter to Malcolm Grant (President and Provost, UCL) and Peter Fonagy (Psychoanalysis Unit, UCL). Accessed April 15, 2014. http://www.ucl.ac.uk/unions/UCU/campaigns/unpaid-internships-letter080812.pdf.

University of Essex. 2013. Junior Research Fellowships. Accessed April 15, 2014. http://www.essex.ac.uk/philosophy/staff/jrf/.

University of Essex. 2014. Philosophy: Junior Research Fellowships. Accessed May 11, 2014. https://www.essex.ac.uk/philosophy/staff/jrf.

Wilson, Tom. 1991. The Proletarianization of Academic Labour. Industrial Relations Journal 22 (4): 250-262.

\section{About the Authors}

Kirsten Forkert

Kirsten Forkert is a lecturer in the School of Media at Birmingham City University. Her research has explored cultural labour, anti-austerity activism, and migration. She is also an activist with the University and College Union.

\section{Ana Lopes}

Ana Lopes is a senior lecturer at the University of the West of England, Bristol. She is associated with the Centre of Employment Studies Research, Faculty of Business and Law. She has written on a variety of topics, including sex work, migrant labour, and community organizing. She is an active member of the University and College Union. 


\section{Appendices: Adverts}

Appendix 1: Honorary Research Assistant, University of Birmingham

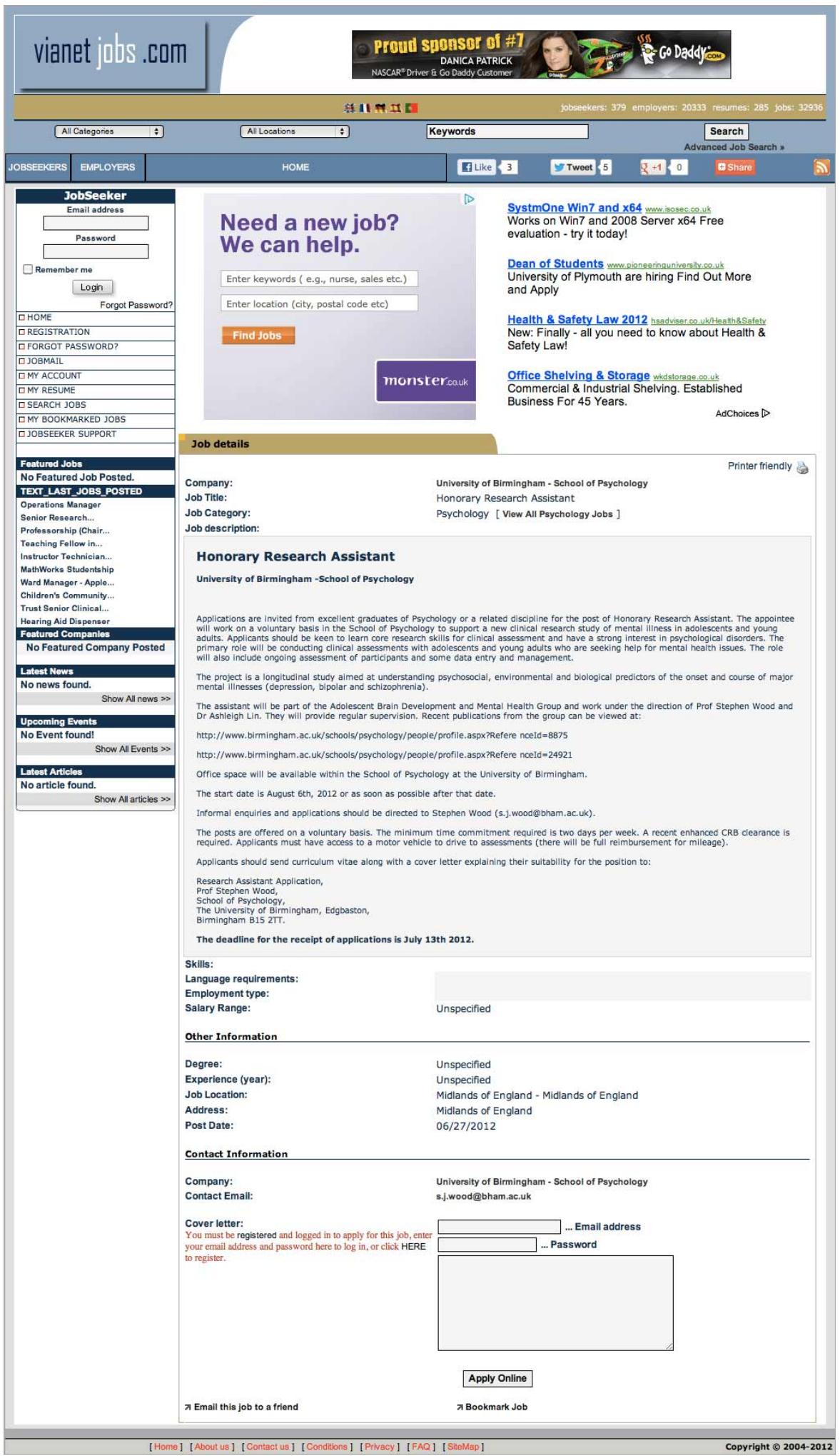

Post archived at: http://www.ucu.org.uk/index.cfm?articleid=6159 
Appendix 2: Research Assistant Internship, University College London

Cemite

\begin{tabular}{|c|c|c|}
\hline In this section & \multicolumn{2}{|c|}{ Research Assistant Internship on the ERIC-D Pilot } \\
\hline \multirow[t]{6}{*}{ Current jobs } & Study & \\
\hline & $\begin{array}{l}\text { Contract } \\
\text { type }\end{array}$ & Fixed-term \\
\hline & $\begin{array}{l}\text { Contract } \\
\text { length }\end{array}$ & From 28th August 2012 for six months \\
\hline & Location & $\begin{array}{l}\text { Research Department of Clinical, Educational and Health Psychology, UCL, 1-19 } \\
\text { Torrington Place, London, WC1E 7HB and Improving Access to Psychological } \\
\text { Therapies (IAPT) services in Camden and Sutton. }\end{array}$ \\
\hline & Salary & Unpaid \\
\hline & Hours & Two or three Full time or Part time positions \\
\hline
\end{tabular}

Search for...

Get involved

Commission us

CAMHS Evidence

Based Practice Unit

Job details

\section{Job details}

The Anna Freud Centre supports distressed children and their families through innovative therapeutic practice and research, training and promoting awareness of mental health issues.

These internships are to assist on the 'Pilot study to Evaluate the Reduction of Increased Cardiovascular risk linked to Depression' (ERIC-D Pilot), which aims to establish the feasibility of conducting a large randomised controlled trial comparing a collaborative-care, exercisefocused enhancement to the treatment provided by the Improving Access to Psychological Therapies (IAPT) programme with standard IAPT treatment for depression.

The interns will be involved in all practical aspects of the research project:

- Recruitment - calling, emailing and sending invitation letters to potential participants. Explaining the project, seeking consent and booking appointments. Liaising with IAPT Psychological Wellbeing Practitioners.

- Data collection - within a session, the interns will complete the consent forms with the participant, carry out pulse wave velocity (PWV) assessments, take measurements of height, weight, blood pressure, and waist circumference, and collect questionnaire data face-to-face with the participant.

- Data entry and analysis - all questionnaire data will be entered by the interns.

- Other administrative duties that from time to time may be required.

These posts offer excellent opportunities to develop research expertise in primary care settings. Candidates should have an interest in working with clinical populations. Data collection will take place at participating IAPT services in Camden and Sutton. Travel expenses will be reimbursed.

Post archived at: https://www.martineve.com/2012/08/02/more-unpaid-academic-positions-andapparent-culture-of-entitlement/ 


\section{Appendix 3: Honorary Junior Research Fellowship, University of Essex}

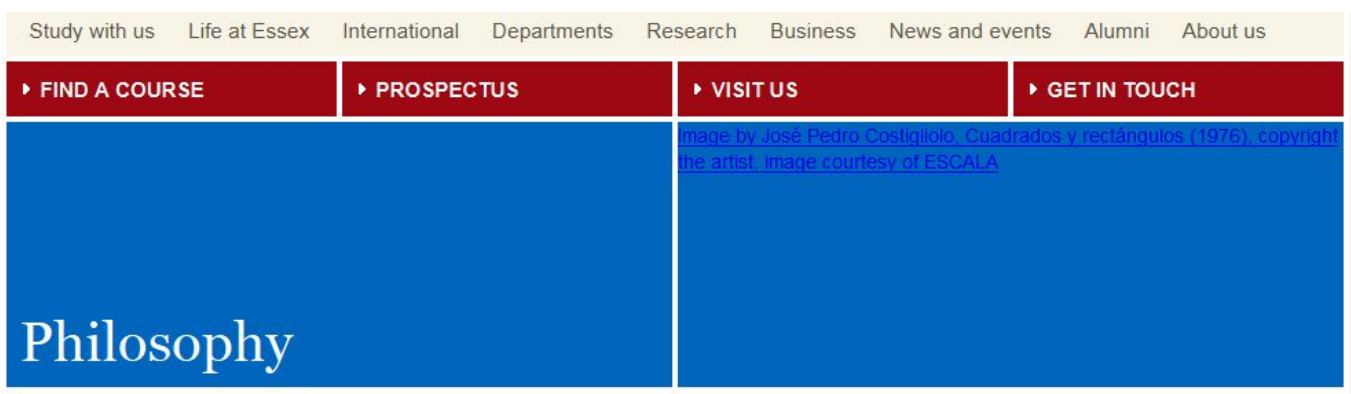

\section{Junior Research Fellows}

\begin{tabular}{l} 
Philosophy home \\
D Undergraduate study \\
Dostgraduate study \\
Dow to apply \\
Dees and scholarships \\
- Research \\
- Stareers and skills \\
\hline About us \\
\hline News and events \\
\hline For current students
\end{tabular}

\section{Current fellows}

- Dr Lisa Grover, e-mail Igrover (non-Essex users add @essex.ac.uk)

- Timothy Secret

\section{About the Junior Research Fellowships}

Our School of Philosophy and Art History offers up to three non-stipendiary Junior Research Fellowships each year, commencing in October. These are available for one year and, in exceptional cases, may be extended for a further period of no more than one year.

Although no salary is attached, Fellows are entitled to shared office space with computing facilities, and the use of all library and School facilities. There are no teaching duties associated with the positions, however Fellows may be entitled to take on teaching, if available, for which they are paid at the usual University rate.

Candidates should have recently completed their $\mathrm{PhD}$, or should have done so by the time their Fellowship starts. Normally applicants will not be considered if more than three years have elapsed since they received their $\mathrm{PhD}$, (exceptions will be made where a candidate's postdoctoral career has been interrupted by, for example, maternity leave, childcare, or illness).

Preference will be given to candidates who have not already held a Junior Research Fellowship in our School or elsewhere. Selection of candidates takes place in June/July each year. For further information about applying for non-stipendary Junior Research Fellowships, please contact our deputy School Administrator Hannah Whiting.

Post archived at:

http://web.archive.org/web/20130603141131/http://www.essex.ac.uk/philosophy/staff/jrf/ 


\section{Appendix 4: Extracurricular teaching, Durham University}

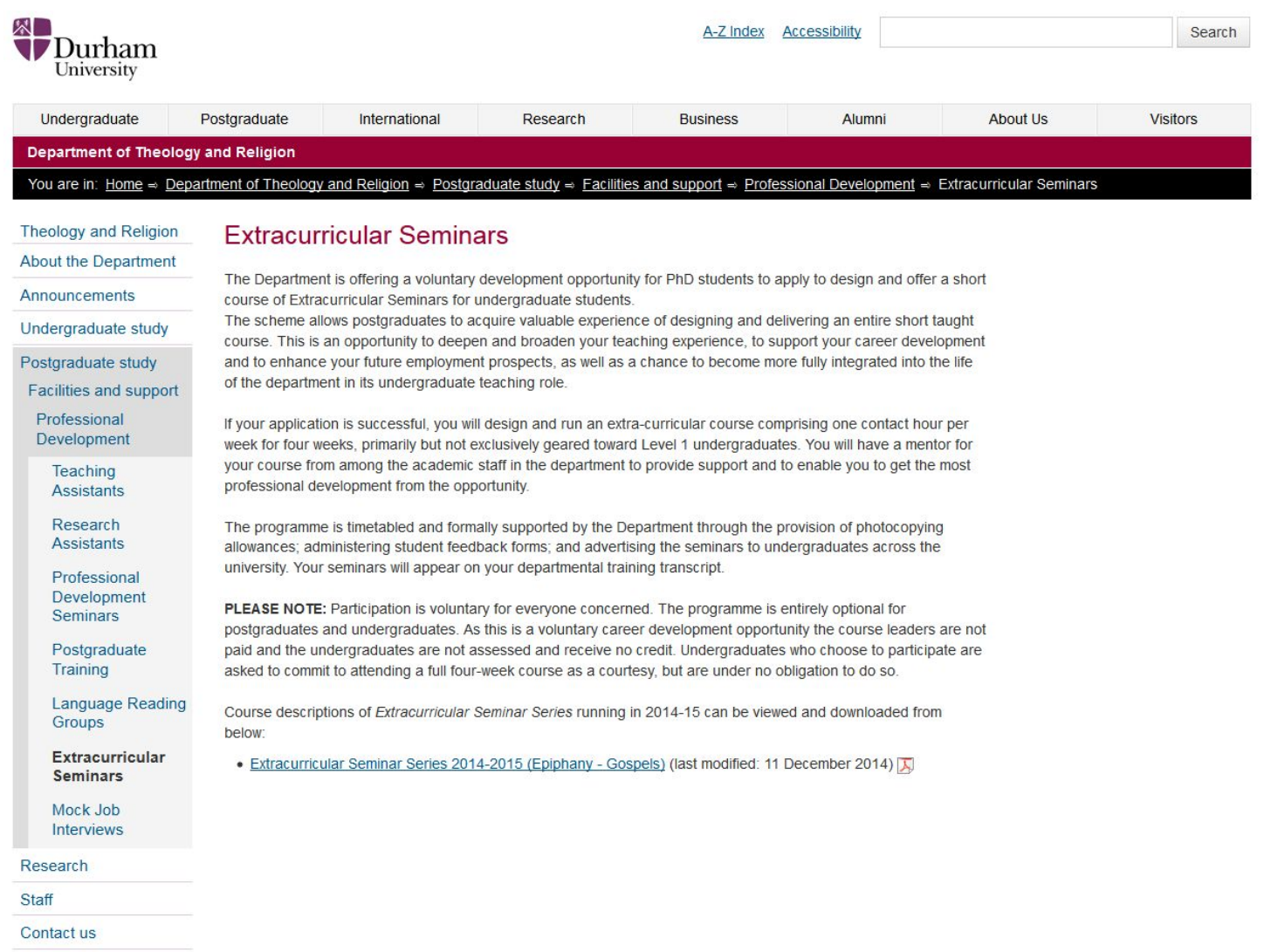

Available at: https://www.dur.ac.uk/theology.religion/postgrad/prof.dev/extracurricular.seminars/ 